\title{
Eco-friendly counter-measures for enlarged basins erosion
}

STEFANO PAGLIARA a, Prof., IAHR Memebr, DESTEC-Department of Energy Engineering, Systems, Land and Construction, University of Pisa, Via Gabba 22, 56122 Pisa, Italy, phone +39 050 2217717; Fax: +39050 2217730; e-mail:s.pagliara@ing.unipi.it

MICHELE PALERMO, Ph.D., IAHR Memebr, DESTEC-Department of Energy Engineering, Systems, Land and Construction, University of Pisa, Via Gabba 22, 56122 Pisa, Italy, phone +39 050 2217929; Fax: +39050 2217730; e-mail:michele.palermo@ing.unipi.it

RAJIB DAS, Ph.D., Assistant Professor, School of Water Resources Engineering, Jadavpur University, Kolkata, India; e-mail: rajibdas79@gmail.com

\begin{abstract}
:
Eco-friendly hydraulic structures (such as block ramps, rock weirs, stepped gabion weir) are generally made of rocks placed in two or more layers on a sloped bed. They are usually used in mountainous rivers to control sediment transport. The downstream stilling basin plays an important role in terms of both energy dissipation and erosion control. In addition, a correct design of the downstream stilling basin can create an optimal habitat for fish species in the river. Therefore, in the present work an attempt was made to control the scour depth downstream of a block ramp using rock structures. In particular, the analysis was focused on scour characteristics in the presence of a protected and enlarged downstream channel. Namely, an abrupt symmetrically enlarged channel was simulated downstream of block ramps. Eco-friendly protection structures, such as rock sills, were tested to limit the erosive process. Rock sills were placed transversally at different longitudinal and vertical positions in the stilling basin and scour morphology variations were investigated. Experiments were carried out for two different ratios of the width of the channel to the width of the ramp and three different ramp slopes. Several scour morphologies were distinguished and classified. In addition, empirical relationships were derived, by which it is possible to estimate the main scour geometry characteristics.
\end{abstract}

Keywords: Eco-friendly structures, Enlargement, Rock Sill, Scour, Stilling Basin

${ }^{a}$ Corresponding Author: STEFANO PAGLIARA, Prof., IAHR Memebr, DESTEC-Department of Energy Engineering, Systems, Land and Construction, University of Pisa, Via Gabba 22, 56122 Pisa, Italy, phone+39050 2217717; Fax: +39050 2217730; e-mail:s.pagliara@ing.unipi.it 


\section{Introduction:}

Eco-friendly hydraulic structures (such as block ramps, rock weirs, stepped gabion weir) are generally used in mountainous rivers. They usually have steep slopes ranging between $10 \%$ and 30 $40 \%$ and their height is generally less than 2-3 meters. Usually a transition from super-critical flow to a sub-critical flow occurs at the toe, resulting in a hydraulic jump which causes scour formation downstream of the structure. Sometimes, the scour depth is big enough to undermine the structure. Therefore, the stilling basin morphology should be studied thoroughly to avoid foundation problems.

The scour characteristics downstream of a block ramp for un-submerged ramp conditions are mainly related to the structure slope, water flow discharge and granulometry of the downstream channel bed material. Erosive process analysis downstream of low-head control structures was conducted by several authors. Among others, Veronese (1937) studied the scour mechanism downstream of a spillway and furnished empirical relations to predict the main geometric parameters. Mason and Arumugam (1985) proposed a critical comparison of the existing formulas to evaluate the maximum scour depth downstream of grade control structures. In particular, local scour downstream of grade control structures was analysed by Bormann and Julien (1991) and D’Agostino and Ferro (2004) who carried out a theoretical investigation on two dimensional jet diffusion and particle stability. Breusers and Raudkivi (1991) proposed a literature review of scour relations and presented guidelines useful for engineering practice.

Many studies on block ramps were also conducted at the University of Pisa under clear water conditions. In particular, Pagliara and Palermo (2008a and 2008b) analyzed the scour process in the presence of rock sills placed in the stilling basin in the case in which the downstream channel has the same width of the ramp. These studies were carried out both with uniform and non-uniform stilling basin material. Successively, Pagliara and Palermo (2010) analysed the effect of the tailwater on scour morphology downstream of a block ramp. They found that this parameter strongly affects the scour geometry, contributing to modify the hydrodynamic of the phenomenon. The previous mentioned studies were conducted in a channel whose width $(B)$ is the same of the ramp $(b)$, i.e., $\lambda=B / b=1$. Very recently, the scour process in a symmetrically enlarged channel has been analysed by Pagliara et al. (2009). Authors conducted experimental tests with two different enlargement ratios $(\lambda=1.8,2.8)$ proposing the following relationships to evaluate the maximum scour hole depth:

$\left(\frac{z_{\max }+h_{0}}{h_{1}}\right)=(11.64 S+0.7) \cdot \exp \left[(-0.64 S+0.17) \cdot F_{d 90}^{*}\right]$

where, $F_{d 90}{ }^{*}$ is defined as equivalent densimetric Froude number and can be calculated as: 
$F_{d 90}^{*}=F_{d 90} \cdot(B / b)^{\left(150.5 S^{2}-43.8 S+3.8\right)}$

Note that $z_{\max }$ is the maximum cross-sectional scour depth, $h_{0}$ is the downstream flow depth (tailwater level), $h_{1}$ is the approaching flow depth at the ramp toe, $S$ is the ramp slope and $F_{d 90}$ is the densimetric Froude number $\left(=v_{1} /\left(g^{\prime} \cdot d_{90}\right)^{1 / 2}\right.$, where $v_{1}$ is the approaching velocity, $d_{90}$ is size of bed material for which $90 \%$ is finer, $g^{\prime}=g\left(\rho_{s^{-}} \rho\right) / \rho$ is the relative gravitational acceleration, $g$ is the gravitational acceleration, $\rho_{s}$ and $\rho$ are the particle and water density, respectively). Equations (1) and (2) are valid in the ranges $1 \leq B / b \leq 2.8,1 V: 8 H \leq S \leq 1 V: 4 H, 1<F_{d 90}<4$ and without any protection structure (no sill) in the stilling basin. The variable $F_{d 90}$ * was introduced to take into account the peculiar hydrodynamic of the phenomenon as the downstream enlargement causes lateral zones of flow re-circulation contributing to axially concentrate the flow exiting from the ramp toe. Thus, $F_{d 90}$ * can be considered as the densimetric Froude number of a flow in a channel $B / b>1$ for which one can obtain the same value of the variable $\left(z_{\max }+h_{0}\right) / h_{1}$ occurring in the enlarged basin taken in consideration.

The analysis of the influence of the stilling basin geometry on the scour process was further developed by Pagliara and Palermo (2011), but, according to authors' knowledge, no studies are present in literature dealing with effect of protection measures on enlarged stilling basin morphology under clear water condition. Therefore, the aim of the present work is to understand the role of protection structures in terms of scour mechanism and equilibrium scour hole geometry. The analysis was conducted inserting opportune rock sills in the stilling basin at different longitudinal and vertical positions. It was observed that they deeply modify the erosive processes and, if opportunely located, they contribute to reduce the main scour hole lengths. The scour morphology was carefully analysed and classified. Useful practical relationships were derived to predict the main scour hole lengths.

\section{Experimental setup:}

Experiments were carried out at the Hydraulics laboratory of University of Pisa, Pisa, Italy, in a rectangular flume $6 \mathrm{~m}$ long, $0.5 \mathrm{~m}$ wide and $0.8 \mathrm{~m}$ deep. Water was supplied to the flume with the help of a centrifugal pump and the discharge was measured by an electronic flow-meter $(0.11 / \mathrm{s}$ accuracy). The water depth and the scour depth were measured using a point gauge $(0.1 \mathrm{~mm}$ accuracy), fitted on a movable trolley placed on the channel.

In order to simulate the different tested enlargement ratios $\lambda=B / b$, the channel was partially narrowed using two metal sheets. The resulting narrow channel width was $b=0.18 \mathrm{~m}$. Ramps were placed in it, thus their width was also $b=0.18 \mathrm{~m}$. Different block ramps configurations were 
analyzed. Namely, three ramp slopes $S$ were tested: $1 \mathrm{~V}: 12 \mathrm{H}, 1 \mathrm{~V}: 6 \mathrm{H}$ and $1 \mathrm{~V}: 4 \mathrm{H}$. For the downstream stilling basin, a loose bed layer, $20 \mathrm{~cm}$ thick and $200 \mathrm{~cm}$ long, was used.

Two different stilling basin enlargements were simulated. The downstream channel widths tested were $B=0.325 \mathrm{~m}$ and $B=0.5$, i.e., $\lambda=1.8$ and $\lambda=2.8$, respectively. Also the downstream part of the channel was narrowed by using movable plexiglass walls which allowed for an optimal visualization of both morphology and hydrodynamic processes occurring in the stilling basin. Figure (1a-b) shows the schematic diagram of the side and plan views and the different tested configurations, along with the main hydraulic and geometric parameters. In addition, Figure (1c) shows a picture of the experimental apparatus (view from downstream). This configuration is relative to experimental tests in the absence of any protection rock sill in the stilling basin (base configuration).

Block ramps were simulated by gluing granular materials on a metal sheet. Both the materials used for block ramps and stilling basin are uniform. Their granulometric characteristics are: $d_{50}=5.75$ $\mathrm{mm}, d_{90}=7.41 \mathrm{~mm}$ and $\sigma=1.2$ for the stilling basin material; $D_{50}=14.8 \mathrm{~mm}, D_{90}=17.86 \mathrm{~mm}$ and $\sigma=1.18$ for the block ramp material. $d_{x x}$ is the diameter for which $x x \%$ of the stilling basin material is finer, $D_{x x}$ is the same for block ramp material, and $\sigma=\left(d_{84} / d_{16}\right)^{0.5}$ is the non-uniformity parameter. For each block ramp and stilling basin configuration, reference tests were carried out, i.e., tests without rock sills in the stilling basin. It means that, for a particular slope and particular enlargement, reference tests were performed to find out the reference values of the maximum scour depth $\left(z_{\max }\right)$ and scour length $\left(l_{0}\right)$ (see also Pagliara and Palermo 2008a-b). Reference tests were repeated several times in order to validate the measured values. Successively, rock sills were placed in the stilling basin and tests were performed again in the same experimental conditions and configuration in order to investigate the variations in scour morphology. The mean diameter of the rocks used for the protection sill was $4.6 \mathrm{~cm}$. They were built using two superimposed layers of rocks in order to not allow any rock displacement during the tests. Figure 2 shows the diagram sketch of the experimental set up with rock sills along with the main hydraulic and geometric parameters. $z_{\text {maxs }}$ and $l_{s}$ are the maximum scour hole depth and length in the presence of a protection structure. Rock sills were placed in the stilling basin at several longitudinal and vertical positions according to the reference values of maximum scour depth $\left(z_{\max }\right)$ and scour length $\left(l_{0}\right)$.

Namely, rock sills were fixed at four different longitudinal positions from the ramp toe, i.e., $x_{s}=0.25 l_{0}, 0.5 l_{0}, 0.75 l_{0}$ and $l_{0}$ from the ramp toe. In addition, three vertical positions $\left(z_{o p}=-0.5 z_{\max }\right.$, $0 z_{\max }$ and $\left.+0.5 z_{\max }\right)$ were tested, in which $z_{o p}$ is the vertical distance of the upper edge of the rock sill from the original bed level (see also Pagliara and Palermo 2008 a-b). Therefore, a total of 12 different positions were examined and they are represented by circle symbols in the diagram sketch 
reported in Figure 3. More specifically, the following non-dimensional longitudinal $\lambda_{s}\left(=x_{s} / l_{0}\right)$ and vertical $Z_{o p}\left(=z_{o p} / z_{\max }\right)$ rock sill positions were tested: $\lambda_{s}=0.25,0.5,0.75,1$ and $Z_{o p}=-0.5,0,+0.5$. In addition, tests were performed also varying the transversal width of the rock sill. Namely, they were carried out using sills whose width was equal to either $b$ or $B$, as shown in Figure 4 . A total of about 300 tests were carried out under clear water conditions.

\section{Result and discussion}

Flow pattern downstream of block ramps in reference tests

The analysis of the scour morphology in the stilling basin is important to understand the differences and similarities characterizing the hydrodynamic behaviour in both straight and enlarged channels. It was noted that in case of a channel having the same width of the ramp $(B / b=1)$, the scour formed downstream is mainly 2D (Pagliara and Palermo 2008a-b). In addition, two different types of hydraulic jump can be distinguished: $F_{M B}$ (free jump in mobile bed) and $S_{M B}$ (submerged jump in mobile bed). Whereas, in the case of an enlarged channel, the scour formed downstream of a block ramp is mainly 3D, such as the hydraulic jump (Hager 1992 and Pagliara et al. 2009). In the tested range of parameters and in the absence of rock sills, Pagliara et al. (2009) noted that the hydraulic jump was entirely located in the stilling basin and the ramp was never submerged. It was also noted that the flow on the ramp was always supercritical. Furthermore, two vortexes (flow re-circulation) occurred downstream of the ramp close to the side walls. The recirculating eddies in the downstream channel cause the flow exiting the ramp to reduce in width, thus increasing the local unit discharge and flow velocity. The exiting flow width reduction is more prominent if $B / b$ increases. In fact, the flow deflection and concentration to the central part of the stilling basin is more prominent increasing $B / b$ (axial deflection of the flow), resulting in a deeper scour hole.

\section{Scour morphology in the presence of protection rock sills}

The scour morphology was investigated for each configuration and flow condition tested. It was observed that the presence of a sill in the stilling basin significantly affects the scour mechanism according to its spatial position. Nevertheless, a preliminary analysis allowed to establish that the two sill typologies tested determines similar morphological variations. It means that no significant differences in scour processes can be detected varying the sill width in the tested ranges of parameters. This is mainly due to the fact that the flow exiting from the ramp toe is axially deflected 
by lateral flow re-circulation, thus the effect of rock sill presence is only significant in the central part of the channel, whereas it becomes negligible close to the channel sides. Pagliara et al. (2008ab) distinguished and classified four scour typologies for $\lambda=1$ and in the presence of rock sills whose width is $B$. Namely, they distinguished scour types R1, R2, R3 and R4. Type R1 occurs when the scour hole is located only downstream of the sill. Conversely, R2 type occurs when the scour hole is located both upstream and downstream of the sill. In this case, the dimensions of the two scour holes formed are comparable, even if, generally, the upstream hole results to be deeper. Types R3 and R4 occur when the scour hole is entirely located upstream of the sill. The difference between these two last types is due to the fact that for R3 type the sill is partially covered by the ridge, whereas for type R4 the sill is completely covered. For symmetrically enlarged channels, some similarities can be pointed out. Namely, also in this case, according to the ramp slope and spatial position of the sill, different scour types were distinguished and classified. In particular, for enlarged channels, R1 type never occurred in the tested range of parameters. This is due to the fact that the flow exiting from the ramp toe is always deflected axially, thus, for all the tested sill positions and hydraulic conditions, the flow had enough energy to form a scour hole just downstream of the ramp toe. Conversely, a new typology was introduced and termed R2*. It is similar to R2 type but it can be considered a transition between type R1 and R2. In fact, it is characterized by two scour holes occurring both upstream and downstream of the sill. Nevertheless, the scour process mainly takes place downstream of it resulting in a scour hole whose dimensions are much more prominent than those characterizing the upstream one. Finally, also for enlarged channels, R3 and R4 types occurred and they have the same characteristics specified above for the case $\lambda=1$. Figure 5 reports four diagram sketches illustrating the described scour types.

As proved by Pagliara and Palermo (2008a-b), the two main parameters affecting the scour typologies are the ramp slope and spatial position of the sill. Authors proposed a graph by which it is possible to predict the scour typology for $\lambda=1$. In the present paper a classification was provided for $1.8 \leq \lambda \leq 2.8$ and for both tested rock sill widths. It has to be noted that it was preliminarily verified that both $\lambda$ and rock sill widths are not influencing the scour classification, therefore it applies for all the conditions and configurations tested in this paper. Namely, in the following, the scour morphology types will be discussed highlighting both the effect of sill position on the scour process and the hydrodynamic behaviour:

(1) case $\lambda_{s}=0.25$

(a) $Z_{o p}=-0.5$ : the exiting jet impacts on the stilling basin and scour process starts. During scour evolution, the rock sill gets exposed, resulting in an overtopping jet which mainly forms a scour hole downstream of the sill. Furthermore, the maximum scour depth upstream of the sill never 
reached the top of the sill. This phenomenon was found similar for all the three slopes tested and for both the sill widths.

(b) $Z_{o p}=0$ : for slopes $1 \mathrm{~V}: 12 \mathrm{H}$ and $1 \mathrm{~V}: 6 \mathrm{H}$ the jet overtops the sill forming a scour hole downstream of it. In the case of high block ramp slope $(1 \mathrm{~V}: 4 \mathrm{H})$, the exiting jet partially impacts on the top of the sill and scour is mainly formed downstream of the structure due to a hydraulic jump formation downstream of it.

(c) $Z_{o p}=+0.5$ : for slopes $1 \mathrm{~V}: 12 \mathrm{H}, 1 \mathrm{~V}: 6 \mathrm{H}$ and $1 \mathrm{~V}: 4 \mathrm{H}$, the jet directly impacts on the sill. The water flows over the structure and a hydraulic jump takes place downstream of it contributing to erode the downstream bed.

In each of the above mentioned cases, R2* scour type occurred.

(2) case $\lambda_{s}=0.5$

$Z_{o p}=-0.5,0$, and +0.5 : the exiting jet impacts on the stilling basin upstream of the sill and proceeds downstream partially overtopping the structure. The hydraulic jump is mainly located upstream of the structure and, eventually, it extends also downstream of it. The scour holes form both upstream and downstream of the sill and their dimensions are comparable. The previous description applies for all the tested slopes. Scour type R2 took place.

(3) case $\lambda_{s}=0.75$

$Z_{o p}=-0.5,0$ and +0.5 : for all the tested ramp slopes, the exiting jet impacts on the stilling basin upstream of the structure. The sill is confining both the hydraulic jump and the scour hole in the upstream part, resulting in a R3 type morphology. The sediment transported downstream forms a ridge which is partially covering the sill.

(4) case $\lambda_{s}=1.00$

(a) $Z_{o p}=-0.5$ : for all the tested ramp slopes, the scour formation occurs only upstream of the sill. Nevertheless, the transported sediment form a ridge which is completely covering the structure. Therefore, a scour type morphology R4 takes place.

(b) $Z_{o p}=0$ : for ramp slope $1 \mathrm{~V}: 12 \mathrm{H}$ the scour hole forms only upstream of the sill and sediment particles transported downstream completely covers the sill. For slope $1 \mathrm{~V}: 6 \mathrm{H}$ it was found that in some tests the sill is partially visible and for some tests the sill was completely covered by the sediment materials, hence this was considered as the transition between two types (R3 and R4). For slope $1 \mathrm{~V}: 4 \mathrm{H}$, the exiting jet impacts on the stilling basin prior to the structure and the scour forms only on the upstream of the sill. The sediment particles are transported downstream forming a ridge, which partially covers the sill structure and type R3 is formed.

(c) $Z_{o p}=+0.5$ : for all the tested ramp slopes, the exit jet impacts on the stilling basin prior to the structure and the scour forms only on the upstream of the sill. The sediment particles are transported 
downstream. Unlike other two conditions $\left(Z_{o p}=-0.5\right.$ and 0$)$, in this case $\left(Z_{o p}=+0.5\right)$ the ridge does not cover the structure and it forms downstream at a distance from the structure. No scour hole is formed downstream of the structure. This is due to the fact that the height of the sill is enough prominent to be covered by the sediment.

Figure 6 synthetizes the classification of the proposed scour types along with the conditions and configurations under which they occur.

In the following Figure 7, examples of the non-dimensional longitudinal profiles are reported for each morphology type illustrated above, where $Z=z / z_{\max }$ and $X=x / l_{s}$ are the non-dimensional vertical and longitudinal coordinates, respectively. From this figure, it is evident that the most effective longitudinal position of the sill is $\lambda_{s}=0.5$, resulting in a significant modification of both sediment transport dynamic and dissipative process. For this position, two well defined scour holes take place both upstream and downstream of the sill. Therefore, the dissipative process is more prominent and efficient. This effect is further amplified by the vertical position of the sill and it results to be more significant when the sill is located at $Z_{o p}=+0.5$. Therefore, the recommended position of the sill for practical application is $\lambda_{s}=0.5$ and $Z_{o p}=+0.5$.

\section{Scour hole depth and length for protected basins}

Pagliara and Palermo (2010) stated that the maximum non-dimensional parameter $\left(z_{\max }+h_{0}\right) / h_{1}$ for $B / b=1$ can be expressed as a function of the following variables:

$\left(z_{\max }+h_{0}\right) / h_{1}=f_{l}\left(F_{d x x}, S\right)$

in which $d_{x x}$ the diameter for which $x x \%$ of sediment is finer. In order to take into account the effect of the stilling basin enlargement, Eq. (3) can be rearranged in the following form:

$Z_{n s}=\left(z_{\max }+h_{0}\right) / h_{1}=f_{1}\left(F_{d x x}, S, B / b\right)$

where $Z_{n s}$ is the non-dimensional group $\left(z_{\max }+h_{0}\right) / h_{1}$.

Pagliara et al. (2009) proposed Eq. (1) where $F_{d 90}{ }^{*}$ can be estimated using Eq. (2). As mentioned above, the previous equation is valid in the range $1 \leq B / b \leq 2.8,0.125 \leq S \leq 0.25,1<F_{d 90}<4$ and without any protection structure (no sill) on the stilling basin. In the present study, the ramp slopes tested varied between $1 \mathrm{~V}: 12 \mathrm{H}(S=0.083)$ and $1 \mathrm{~V}: 4 \mathrm{H}(S=0.25)$. For this reason, the first step of data elaboration was to validate Eq. (1) in a wider range of ramp slope. Namely, Eq. (1) predicting capability was tested using experimental data relative to $S=0.083$ and for $1 \leq B / b \leq 2.8$. It was proved that Eq. (1) satisfactorily predicts also data for $S=0.083\left(R^{2}=0.93\right)$, therefore its range of validity can be assumed as follows: $1 \leq B / b \leq 2.8,0.083 \leq S \leq 0.25,1<F_{d 90}<4$. 
Nevertheless, in the present study, a protection structure was located in the stilling basin, hence, according to Pagliara and Palermo (2008a), the functional relationship reported in Eq. (4) can be rearranged as follows:

$Z_{S}=\left(z_{\operatorname{maxs}}+h_{0}\right) / h_{1}=f_{1}\left(F_{d x x}, S, B / b, \lambda_{s}, Z_{o p}\right)$

where, $\lambda_{s}$ and $Z_{o p}$ are the longitudinal and vertical non-dimensional positions of the protection structures in the stilling basin, $z_{\operatorname{maxs}}$ is the maximum scour depth in the presence of a sill and $Z_{s}$ is the non-dimensional group $\left(z_{\operatorname{maxs}}+h_{0}\right) / h_{1}$. Preliminary data analysis allowed to state that the different sill widths tested are not affecting the scour process, therefore the width of the sill is not appearing in Eq. (5). Successively, elaborations were conducted in such a way to take into account the effect of each non dimensional additive parameter in order to modify the reference relationship valid in the absence of protection sills (Eq. 1). Namely, the effect of both $\lambda_{s}$ and $Z_{o p}$ on the scour process was evaluated. In particular, the analysis of data was preliminary conducted for $B / b=1.8$. Figure $8 \mathrm{a}-$ c reports the experimental points in a graph $\left[Z_{s} / Z_{n s}\right]\left(\lambda_{s}\right)$ for different slopes $S$ and $Z_{o p}$, i.e., for $Z_{o p}=+0.5$ (Figure 8a), $Z_{o p}=0$ (Figure 8b) and $Z_{o p}=-0.5$ (Figure 8c). In this case, $Z_{s}$ is the experimental value of the non-dimensional group $\left(z_{\operatorname{maxs}}+h_{0}\right) / h_{1}$, whereas $Z_{n s}$ is the calculated value of the nondimensional group $\left(z_{\max }+h_{0}\right) / h_{1}$ using Eq. (1).

From previous graphs some general deductions can be derived. Namely, Figure 8 a shows that $Z_{s}<Z_{n s}$ for all the tested $\lambda_{s}$, i.e. the non-dimensional scour depth in the presence of the protection sill is less than that estimated for the same configuration and hydraulic conditions in the respective reference test (absence of structure). Furthermore, comparing Figure $8 \mathrm{a}$ with $8 \mathrm{~b}$ and $8 \mathrm{c}$, it is evident that the most efficient non-dimensional vertical position of the rock sill in terms of scour depth reduction is $Z_{o p}=+0.5$, for all the tested conditions. This is mainly due to the fact that a sill located at $Z_{o p}=+0.5$ determines a more prominent obstacle for the flow exiting from the ramp toe, resulting in an increase of the local tailwater level, which enhances the turbulent mixing and energy dissipation. A confined vortex upstream of the sill takes place and the flow exiting from the ramp toe generally directly impacts on the sill, reducing its erosive capacity. The scour reduction effect is bigger for lower slopes and, generally, for $\lambda_{s}=0.5$ (see Figure $8 \mathrm{a}-\mathrm{c}$ ). This occurrence is mostly due to the fact that for lower ramp slopes, the exiting flow horizontal velocity component is more prominent, resulting in a more significant reduction of the erosive jet action, because of the impact on the sill. In addition, for $\lambda_{s}=0.5, \mathrm{R} 2$ scour morphology type is occurring. It means that the flow energy is dissipated both upstream and downstream of the sill, as two scour holes take place. Similar observations can be also done for $B / b=2.8$. Figure $9 \mathrm{a}-\mathrm{b}$ is comparing the trend of $Z_{s} / Z_{n s}$ for the same hydraulic conditions and vertical sill location $\left(Z_{o p}=+0.5\right)$, but for the two different tested enlargement ratios, i.e. for $B / b=1.8$ and 2.8. The proposed figures are relative to ramp slopes 
$S=0.167$ (Figure 9a) and $S=0.25$ (Figure 9b). It can be observed that the scour phenomenon behavior, in the presence of the sill, is practically very similar for both $B / b$ tested, i.e. for each tested slope the effect of $B / b$ is not very prominent. This occurrence was found valid for all $Z_{o p}$ tested. Therefore, general qualitative observations derived for $B / b=1.8$ can be considered valid also for $B / b=2.8$. It means that for design purposes, the most efficient position in terms of scour depth reduction is $Z_{o p}=+0.5$ and $\lambda_{s}=0.5$.

Based on the deductions exposed above and on the functional relationship reported in Eq. (5), the following equation is proposed in order to evaluate the non-dimensional scour depth and it is valid for $1<F_{d 90}<4,0.083 \leq S \leq 0.25,0.25 \leq \lambda_{s} \leq 1,1.8 \leq B / b \leq 2.8$ and $-0.5 \leq Z_{o p} \leq+0.5$.

$$
\left(\frac{z_{\operatorname{maxs}}+h_{0}}{h_{1}}\right)=\left(\frac{z_{\max }+h_{0}}{h_{1}}\right)_{E q .(1)} \cdot f_{1}\left(Z_{o p}\right) \cdot f_{2}\left(S, \frac{B}{b}\right) \cdot f_{3}\left(\lambda_{s}\right)
$$

where $\left[\left(z_{\max }+h_{0}\right) / h_{1}\right] E q .(1)$ is the value of non-dimensional scour depth evaluated using Eq. (1) and:

$f_{1}\left(Z_{o p}\right)=-0.15 Z_{o p}^{2}-0.33 Z_{o p}+0.93$

$f_{2}\left(S, \frac{B}{b}\right)=-3.39 S^{2}+2.21 S+\left(\frac{B}{b}\right)^{-0.43}$

$f_{3}\left(\lambda_{s}\right)=0.43 \lambda_{s}^{2}-0.29 \lambda_{s}+0.98$

Figure 10a shows the comparison between measured and calculated (with Eq. 6) values of the nondimensional parameter $\left[\left(z_{\operatorname{maxs}}+h_{0}\right) / h_{1}\right]$ for all the experimental data. It can be observed that Eq. (6) well predicts the totality of data $\left(\mathrm{R}^{2}=0.84\right)$.

A similar analysis was conducted to evaluate the non-dimensional scour hole length $L_{\mathrm{s}}=l_{\mathrm{s}} / h_{1}$. It is evident that the parameter $L_{s}$ is depending on the same non-dimensional independent parameters reported in Eq. (5). Nevertheless, according to Breusers and Raudkivi (1991) the maximum nondimensional scour length can be expressed as a function of the non-dimensional scour depth. This occurrence can be considered valid for scour phenomena in the absence of any protection structures and, in general, for not enlarged channels. However, the aim of the present paper is to find a simple and unique empirical expression by which to evaluate the parameter $L_{s}$. Therefore, the analysis of experimental data was conducted in such a way to derive a general equation for $L_{s}$ as a function of the non-dimensional parameter $\left[\left(z_{\operatorname{maxs}}+h_{0}\right) / h_{1}\right]$ and the non dimensional indipendent groups reported in the functional relationship Eq. (5). The following Eq. (10) was derived

$L_{S}=\left(\frac{z_{\operatorname{maxs}}+h_{0}}{h_{1}}\right)_{E q \cdot(6)} \cdot g_{1}(S) \cdot g_{2}\left(\lambda_{s}\right) \cdot g_{3}\left(Z_{o p}\right)$

Where $\left[\left(z_{\operatorname{maxs}}+h_{0}\right) / h_{1}\right]_{E q .(6)}$ is the estimated value of the non-dimensional parameter $\left[\left(z_{\operatorname{maxs}}+h_{0}\right) / h_{1}\right]$ derived using Eq. (6) and 


$$
\begin{aligned}
& g_{1}(S)=3 S^{-0.24} \\
& g_{2}\left(\lambda_{s}\right)=-0.046 \lambda_{s}^{2}-0.084 \lambda_{s}+0.43 \\
& g_{3}\left(Z_{o p}\right)=1.82 Z_{o p}+2.69
\end{aligned}
$$

Figure 10b shows the comparison between measured and calculated (using Eq. 10) values of the variable $L_{s}$. It can be observed that the proposed equation well predicts the totality of experimental data $\left(\mathrm{R}^{2}=0.81\right)$. The previous Eq. (10) is valid in the same range of parameters of Eq. (6).

Nevertheless, a safety multiplicative coefficient $K$ is recommended, according to the importance of the structure and due to the uncertainties in evaluating the hydraulic parameters in field applications. The recommended coefficient $K$ can range between 1.3 and 2 . For design purposes, it can be used for the application of the proposed equations.

\section{Conclusions}

In the present paper the scour process occurring in an enlarged channel downstream of a block ramp in the presence of protection sills was studied and analyzed. Namely, experimental tests were conducted for different ramp slopes, enlargement ratios and hydraulic conditions. It was experimentally proven that the presence of a rock sill deeply affects the scour morphology in the stilling basin. Four different scour morphology types were distinguished and classified. As for straight channels, the scour morphology types mainly are depending on the non-dimensional longitudinal sill position $\lambda_{s}$ and ramp slope $S$. This is due to the fact that both the longitudinal position of the sill $x_{s}$ inside the scour hole and the impinging angle of the exiting flow from the ramp toe are the main parameters affecting the scour hole configuration. Furthermore, it was proven that in the tested range of parameters the width of the sill does not affect the scour process, as the flow exiting from the ramp toe is axially concentrated. The analysis of experimental data showed that the scour depth is mainly depending on the hydraulic conditions and on the spatial position of the sill. It was experimentally proven that, in general, the most efficient spatial position of the sill in terms of scour depth reduction is $Z_{o p}=+0.5$ and $\lambda_{s}=0.5$. In fact, this spatial location of the sill in the stilling basin causes two scour holes formation (both upstream and downstream of the sill). Therefore the dissipative process is more prominent and efficient as it occurs between upstream and downstream sections. Two empirical equations were derived by which one can evaluate both the non-dimensional scour depth and the non-dimensional scour hole length in the presence of a rock made sill. 


\section{Acknowledgments}

The three authors equally contributed to the paper.

\section{Notations:}

$b \quad=$ width of the ramp

$B \quad=$ channel width (width of the stilling basin)

$D_{x x} \quad=$ size of ramp material for which $\mathrm{xx} \%$ is finer

$d_{x x} \quad=$ size of bed material for which $\mathrm{xx} \%$ is finer

$f_{1}, f_{2}, f_{3}=$ function

$F_{d \mathrm{xx}}=v_{1} /\left(g^{\prime} \cdot d_{90}\right)^{1 / 2}$, densimetric Froude number

$F^{*} d \mathrm{xx}=F_{d x x} \cdot(B / b)^{\left(150.5 S^{2}-43.8 S+3.8\right)}$, equivalent densimetric Froude number

$g_{1}, g_{2}, g_{3}=$ function

$g \quad=$ gravitational acceleration

$g^{\prime} \quad=g\left(\rho_{s}-\rho\right) / \rho$, reduced gravitational acceleration

$K \quad=$ safety coefficient

$h_{0} \quad=$ downstream flow depth (tailwater level)

$h_{1} \quad=$ approaching flow depth at the ramp toe

$l_{0} \quad=$ scour hole length in reference tests

$L_{0} \quad=l_{0} / h_{1}$, dimensionless scour hole length in reference tests

$l_{s} \quad=$ scour hole length in tests with protection structure

$L_{s} \quad=l_{\mathrm{s}} / h_{1}$, dimensionless scour hole length in tests with protection structure

$Q \quad=$ inflow discharge

$S \quad=$ block ramp slope

$v_{1}=$ average approaching flow velocity at the ramp toe

$x_{s} \quad=$ longitudinal location of the sill

$x \quad=$ longitudinal coordinate

$X=x / l_{s}$, dimensionless longitudinal coordinate

$z \quad=$ vertical coordinate

$z_{\max }=$ maximum scour depth in reference tests

$z_{\text {maxs }}=$ maximum scour depth in tests with protection structure

$z_{o p} \quad=$ vertical position of sill in the stilling basin

$Z \quad=z / z_{\operatorname{maxs}}$, dimensionless vertical coordinate

$Z_{o p} \quad=z_{o p} / z_{\max }$, dimensionless vertical position of sill

$Z_{n s}=\left(z_{\max }+h_{0}\right) / h_{1}$, dimensionless maximum scour depth in reference tests 
$Z_{s}=\left(z_{\operatorname{maxs}}+h_{0}\right) / h_{1}$, dimensionless maximum scour depth in tests with protection structure

$\lambda \quad=B / b$, enlargement ratio

$\lambda_{s}=x_{s} / l_{0}$, dimensionless longitudinal position of the sill

$\sigma \quad=\left(d_{84} / d_{16}\right)^{0.5}$, sediment non-uniformity parameter

$\rho \quad=$ water density

$\rho_{s} \quad=$ sediment density

\section{Reference:}

Bormann E, Julien PY 1991. Scour downstream of grade control structures. Journal of Hydraulic Engineering 117 : $579-594$.

Breusers HNC, Raudkivi AJ 1991. Scouring. IAHR Hydraulic structures design manual 2, Balkema: Rotterdam, the Netherlands.

D'Agostino V, Ferro V 2004. Scour on alluvional bed downstream of grade-control structures. Journal of Hydraulic Engineering 130 : 1-14.

Hager WH 1992. Energy dissipators and hydraulic jump. Water Science \& Technology Library 8. Kluwer: Dordrecht.

Mason PJ, Arumugam K 1985. Free jet scour below dams and flip buckets. Journal of Hydraulic Engineering 111 : 220-235.

Pagliara S, Palermo M 2008a. Scour control downstream of block ramps. Journal of Hydraulic Engineering 134 : 1376-1382.

Pagliara S, Palermo M 2008b. Scour control and surface sediment distribution downstream of block ramps. Journal of Hydraulic Research 46 : 334-343.

Pagliara S, Palermo M, Carnacina I 2009. Scour and hydraulic jump downstream of block ramps in expanding stilling basins. Journal of Hydraulic Research 47 : 503-511.

Pagliara S, Palermo M 2010. Influence of tailwater depth and pile position on scour downstream of block ramps. Journal of Irrigation and Drainage Engineering. 136 : 120-130.

Pagliara S, Palermo M 2011. Effect of stilling basin geometry on clear water scour morphology downstream of a block ramp. Journal of Irrigation and Drainage Engineering. 137 : 593601.

Veronese A 1937. Erosioni di fondo a valle di uno scarico. Annali Lavori Pubblici 75 : 717-726 [in Italian]. 


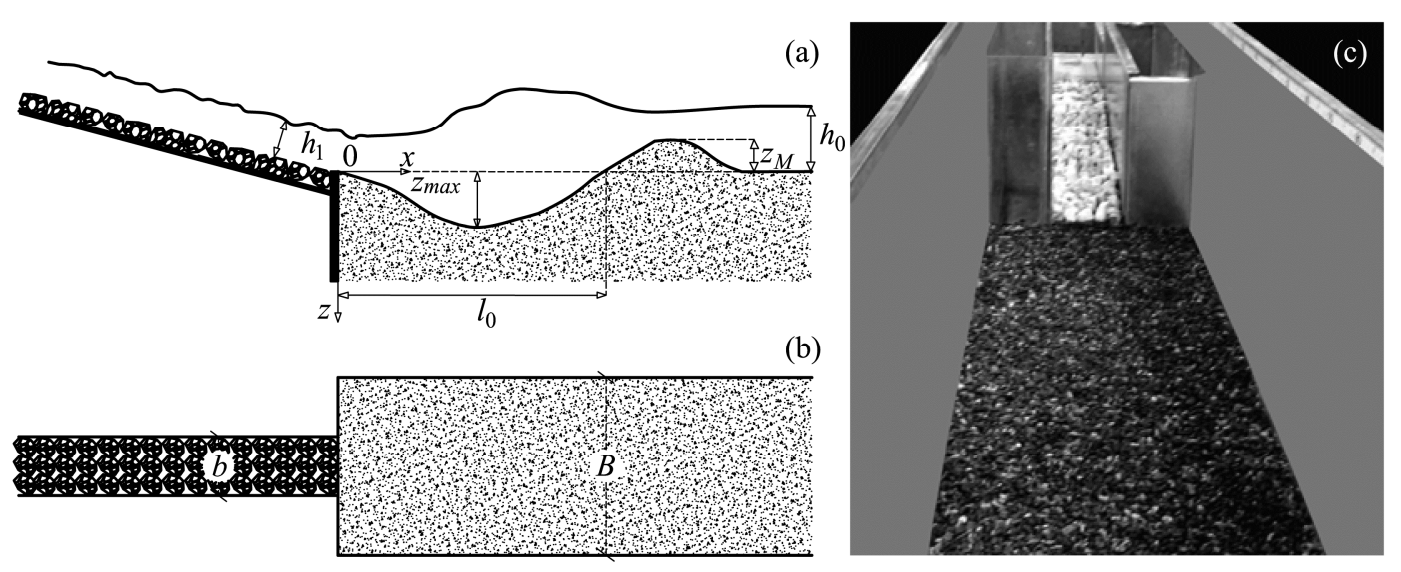

Figure 1 Schematic diagram of the experimental setup for reference tests: (a) side view and (b) plan view; (c) picture of experimental setup. 


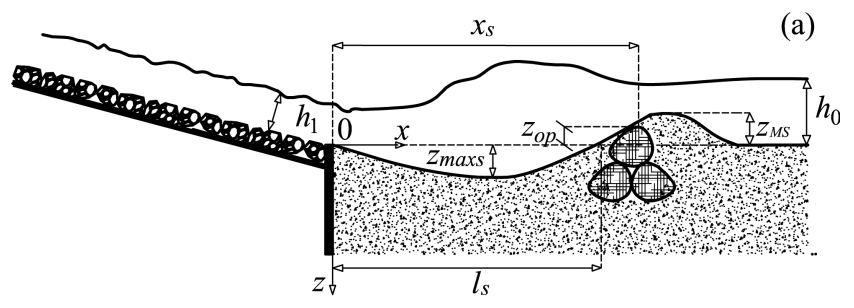

(b)

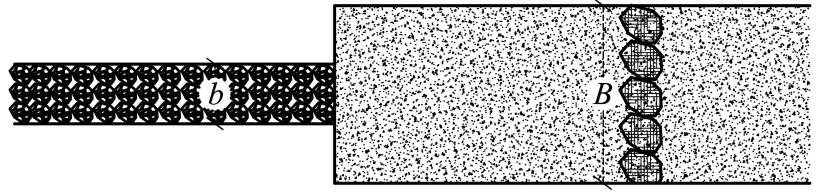

Figure 2 Diagram sketch of the experimental set up for protected stilling basin: (a) side view and (b) plan view 


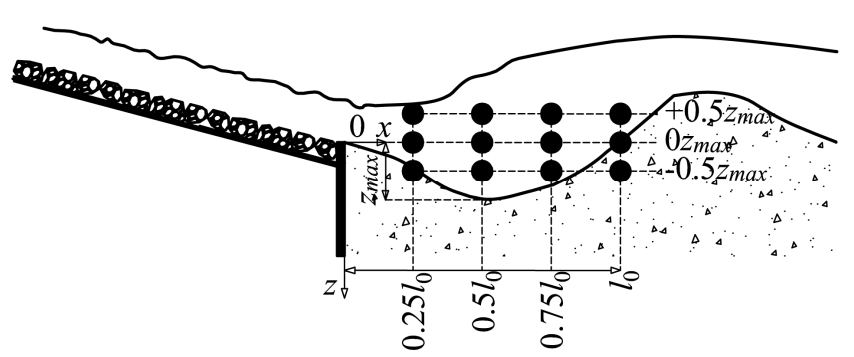

Figure 3 Schematic diagram showing the different sill positions tested. 

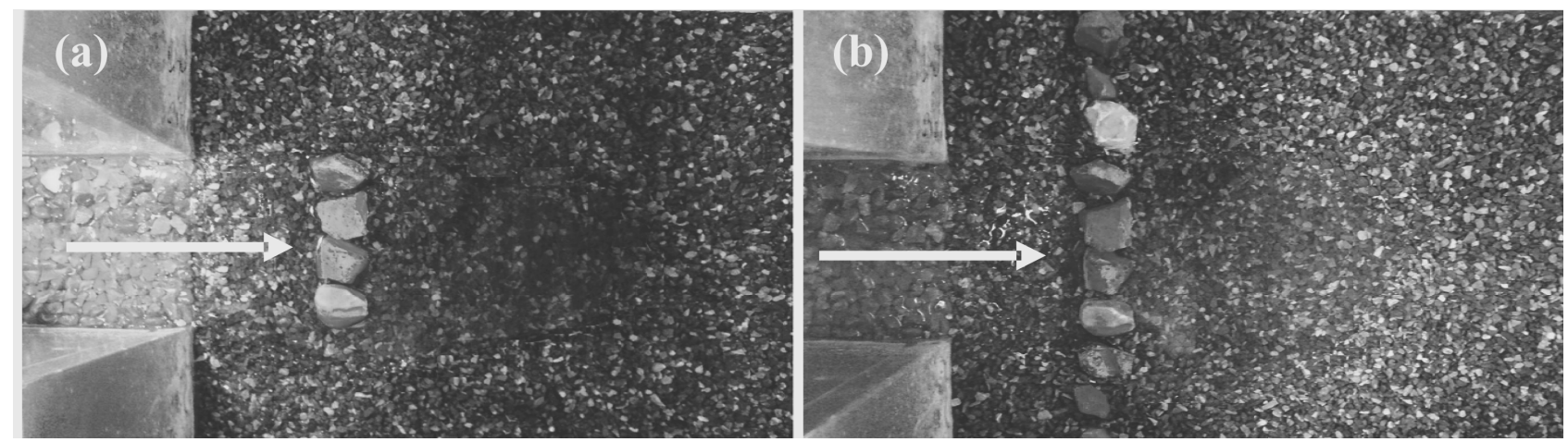

Figure 4 Picture showing different tested sills: (a) sill width $=b$ and (b) sill width $=B$ 

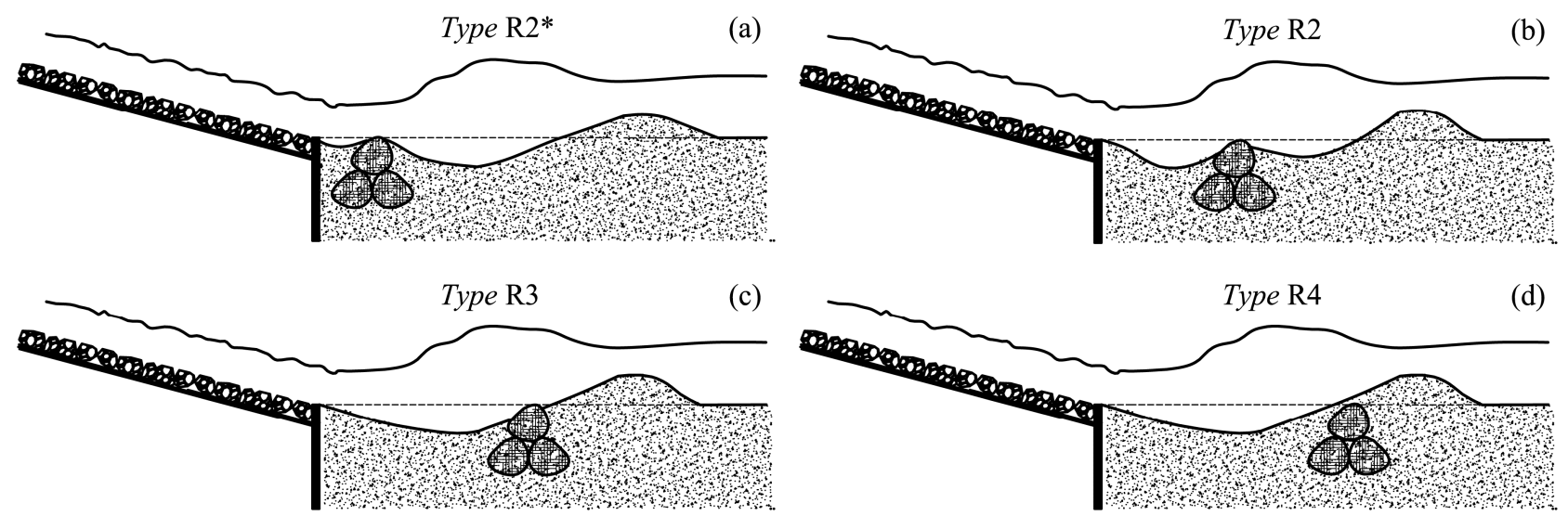

Figure 5 Sour Types: (a) R2*, (b) R2, (c) R3 and (d) R4. 


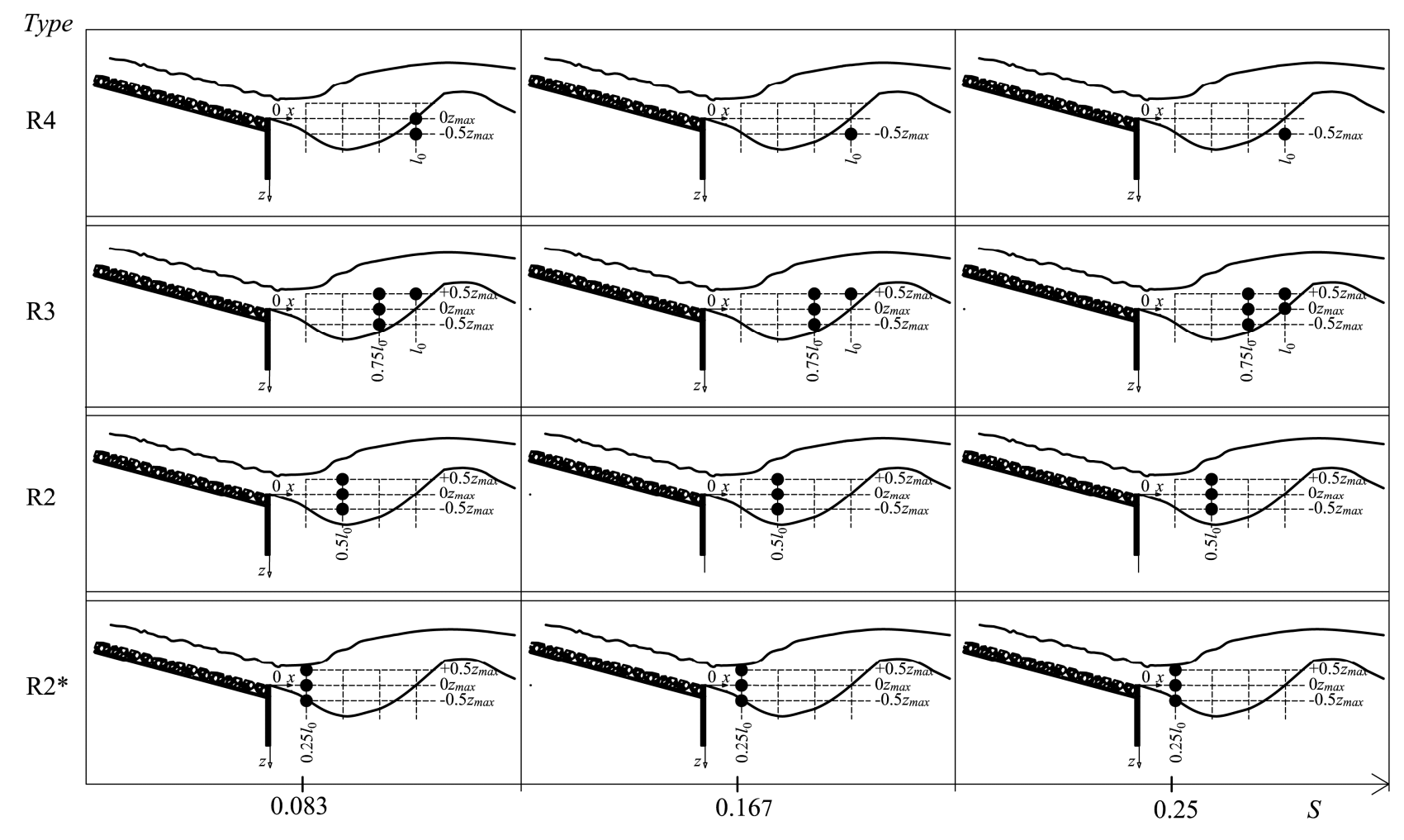

Figure 6 Scour types for different sill locations and block ramp slopes (not in scale) 

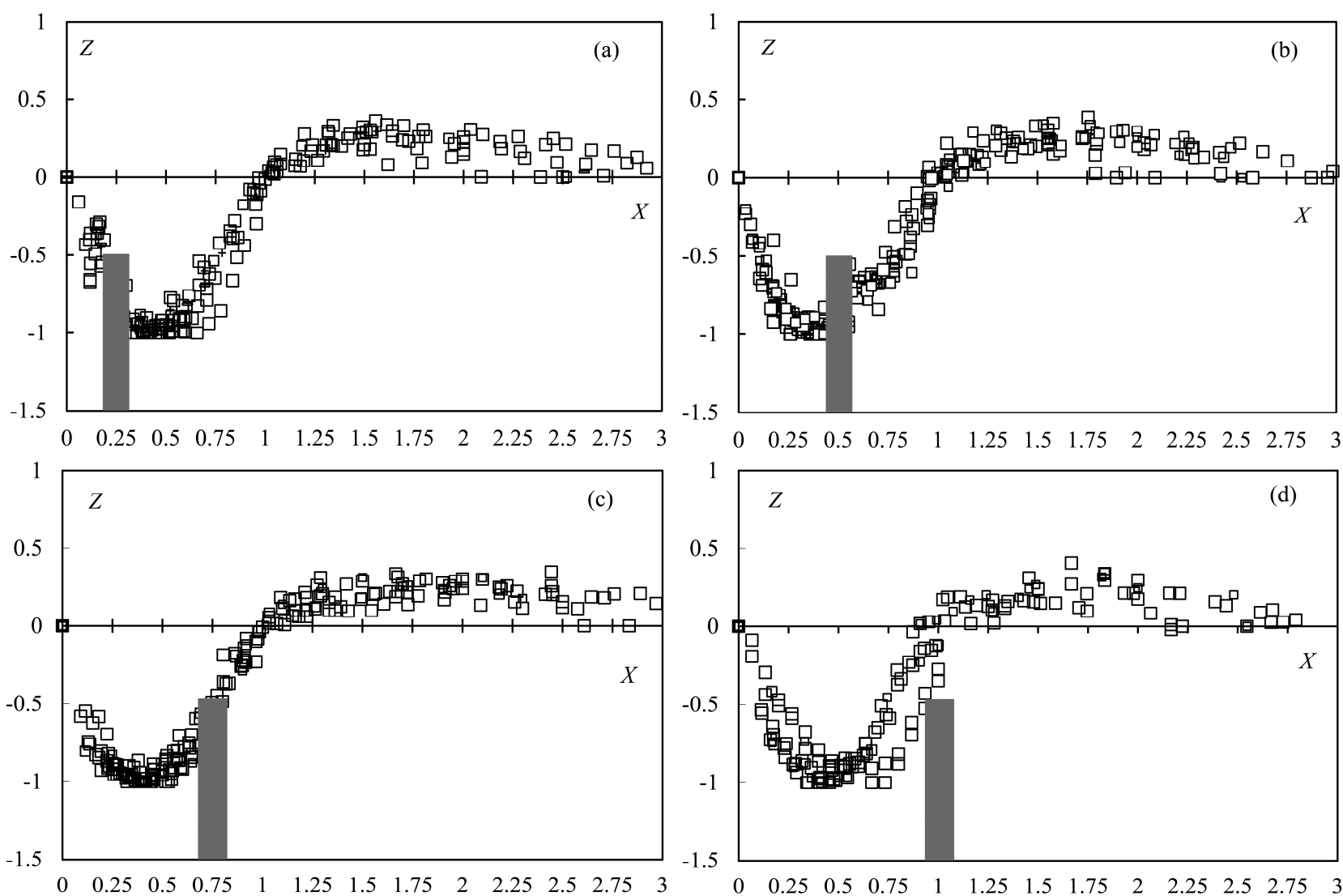

Figure 7 Examples of non-dimensional longitudinal scour profiles for all the tested slopes, $Z_{o p}=-0.5$ and: (a) for $\lambda_{s}=0.25$ (Type R2*); (b) for $\lambda_{s}=0.50$ (Type R2); (c) for $\lambda_{s}=0.75$ (Type R3); (d) for $\lambda_{s}=1$ (Type R4) 

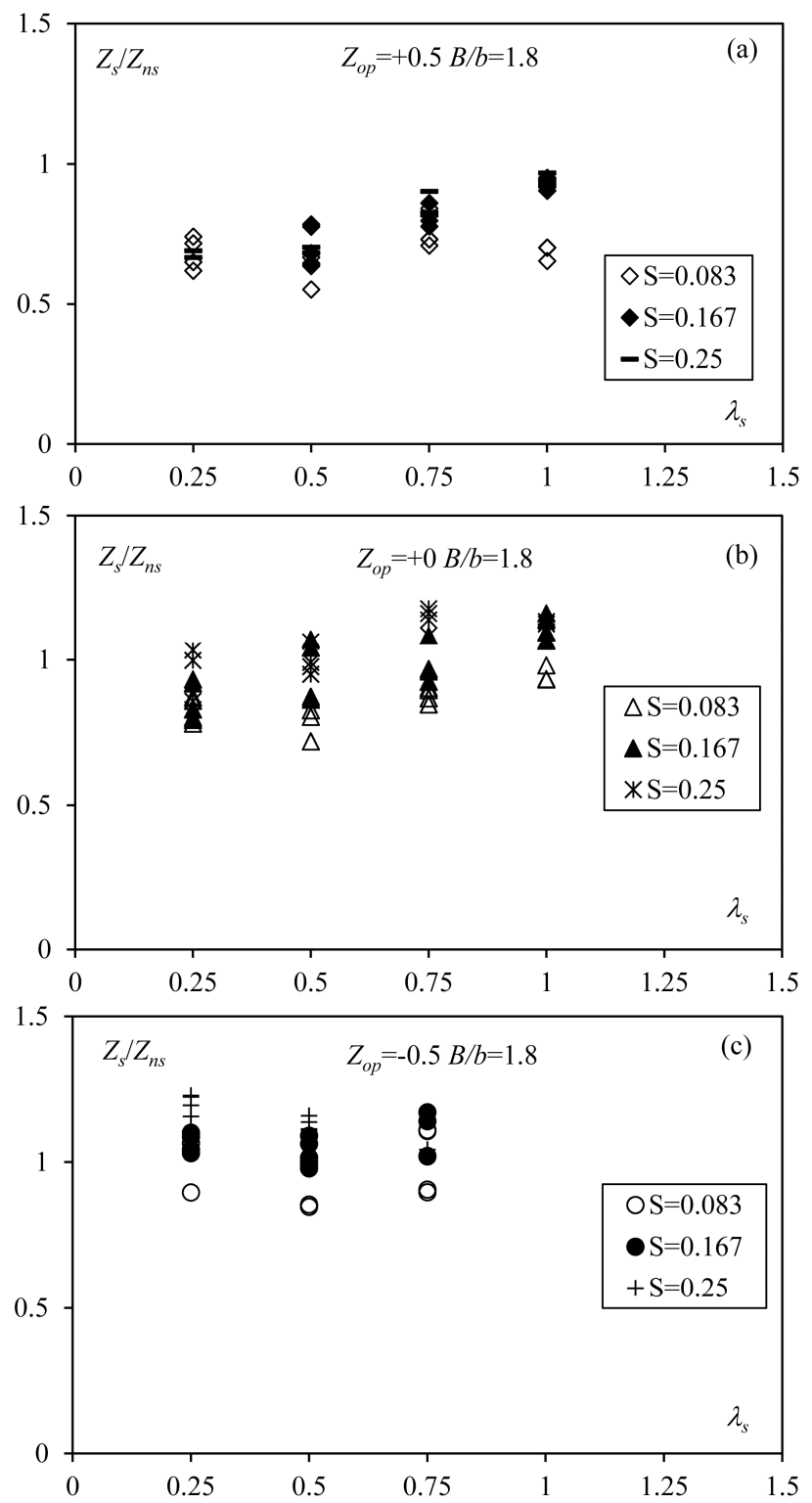

Figure $8 Z_{s} / Z_{n s}$ versus $\lambda_{s}$ for $B / b=1.8$, for all tested slopes $S$ and (a) for $Z_{o p}=+0.5$, (b) $Z_{o p}=0$, (c) $Z_{o p}=-0.5$. 


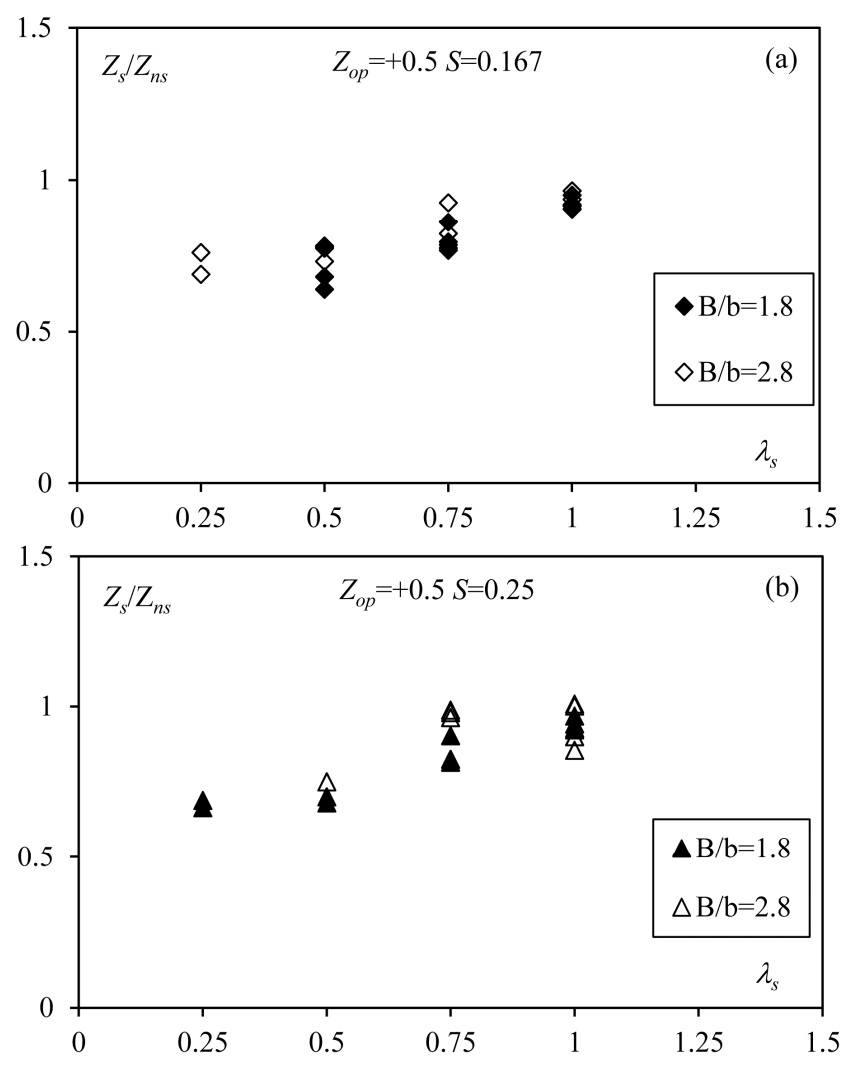

Figure $9 Z_{s} / Z_{n s}$ versus $\lambda_{s}$ for $Z_{o p}=+0.5$, for all tested $B / b$ and (a) for $S=0.167$ and (b) $S=0.25$. 

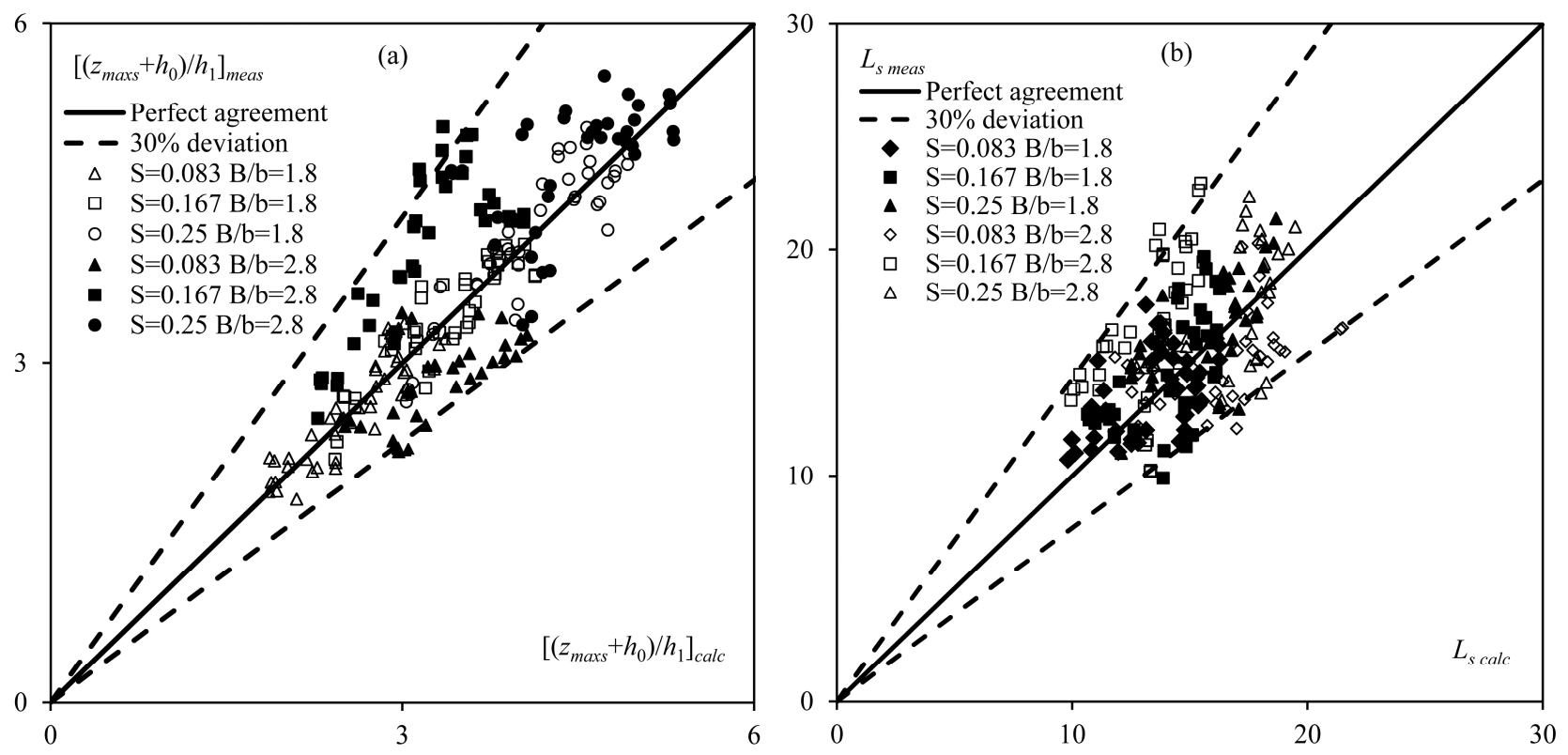

Figure 10 (a) Comparison between measured and calculated (with Eq. 6) values of the parameter $\left[\left(z_{\operatorname{maxs}}+h_{0}\right) / h_{1}\right] ;(b)$ Comparison between measured and calculated (with Eq. 10) values of the parameter $L_{s}$. 